\title{
FORMAÇÃO DE PROFESSORES DE MÚSICA: CONTRIBUIÇÕES A PARTIR DE UMA PESQUISA SOBRE O CONTEXTO ARGENTINO
}

\author{
Music teacher education: contributions from \\ a research on the Argentine context
}

\author{
Formación de profesores de música: \\ contribuciones desde una investigación sobre \\ el contexto argentino
}

\author{
GiSLENE MARINO \\ Universidade do Estado de Minas Gerais \\ gislene.marino@uemg.br \\ JúLIo Emílio DinIZ-PEREIRA \\ Universidade Federal de Minas Gerais \\ juliodiniz@ufmg.br
}

\begin{abstract}
Resumo: Este artigo apresenta dados e análises de uma pesquisa que buscou compreender concepções e modelos de formação de professores de música na Argentina. A investigação fundamentou-se nos paradigmas de formação docente, nos modelos de formação de professores de música e no conceito de habitus conservatorial. Foram realizados três grupos focais com alunos e 18 entrevistas com professores de uma universidade, uma escola de música popular e um conservatório de música na Argentina, além de consultas a documentos oficiais e projetos pedagógicos daquele país. Dentre outros aspectos, verificou-se a coexistência de um modelo que foca a formação do músico e outro que foi designado "quarto modelo" ou "modelo de formação do professor de música", pois busca o equilíbrio entre conteúdos pedagógicos e conteúdos musicais. Os resultados desta pesquisa podem contribuir para discussões no campo de estudo da formação de professores de música, especialmente na América Latina, incluindo o Brasil.
\end{abstract}

Palavras-chave: Formação de professores de música na Argentina. Concepções de formação docente. Modelos de formação de professores de música.

\begin{abstract}
This paper presents data and analyzes of a research that sought to understand conceptions and models for music teacher education in Argentina. The research was based upon the discussion about teacher education paradigms and, more specifically, on music teacher education models as well as on the concept of conservatory habitus. Three focus groups were done with students and 18 interviews with teacher educators from one university, one popular music school and one music conservatory in Argentina, in addition to consulting official documents and pedagogical projects from this country. Among other aspects, there was the coexistence of a model that focuses on the training of the musician and another that was called "the fourth model" or "model for the music teacher education", as it seeks a balance between pedagogical content and musical content. Based upon the results of this research, it intends to contribute to discussions in the study field of Music teacher education, especially in Latin America, including Brazil.
\end{abstract}

Keywords: Music teacher education in Argentina. Conceptions of teacher education. Models of music teacher education. 


\begin{abstract}
Resumen: Este artículo presenta datos y análisis de una investigación que buscó comprender concepciones y modelos para la formación de profesores de música en Argentina. La investigación se basó en los paradigmas de la formación de profesores, en los modelos de formación de profesores de música y en el concepto de habitus conservatorial. Se realizaron tres grupos focales con estudiantes y 18 entrevistas con profesores de una universidad, una escuela de música popular y un conservatorio de música en Argentina, además de consultas a documentos oficiales y proyectos pedagógicos en ese país. Entre otros aspectos, hubo la coexistencia de un modelo que se enfoca en la formación del músico y otro que fue designado como "cuarto modelo" o "modelo de formación del profesor de música”, ya que busca un equilibrio entre los contenidos pedagógicos y musicales. Los resultados de esta investigación pueden contribuir a las discusiones en el campo de estudio de formación de profesores de música, especialmente en América Latina, incluido Brasil.
\end{abstract}

Palabras clave: Formación de profesores de música en Argentina. Concepciones de formación docente. Modelos de formación de profesores de música.

\title{
INTRODUÇÃO
}

Este artigo pretende contribuir para discussões sobre a formação de professores de música, ao trazer análises da pesquisa de doutorado que teve como objetivo compreender as concepções e os modelos de formação inicial de professores de música na Argentina. A investigação teve como fundamento os paradigmas de formação docente (Zeichner, 1983), os modelos de formação de professores de música (Mateiro, 2010) e o conceito de habitus conservatorial (Pereira, 2013). A coleta dos dados deu-se por meio de consulta a documentos oficiais e projetos pedagógicos, da realização de três grupos focais com alunos e de 18 entrevistas com professores de uma universidade, uma escola de música popular e um conservatório de música. O material recolhido foi avaliado por meio da técnica de análise de conteúdo (Bardin, 2009).

A formação dos professores de música na Argentina ocorre em instituições universitárias, mas, em sua maioria, em instituições de caráter não universitário, tendo como uma das principais concepções o professor como agente social, reflexivo, ativo e autônomo. Foram observados indícios do habitus conservatorial (Pereira, 2013) e características dos paradigmas "comportamentalista", "tradicional-artesanal", "personalista" e "baseado na pesquisa" (Zeichner, 1983). Verificou-se a coexistência de um modelo que foca a formação do músico (Mateiro, 2010) e outro, que foi designado "quarto modelo" ou "modelo de formação do professor de música", pois busca o equilíbrio entre conteúdos pedagógicos e conteúdos musicais.

Em decorrência deste estudo, focado na Argentina, pode-se extrair questionamentos e propostas para o contexto brasileiro em que cursos de licenciatura em música têm passado por reformulações a fim de fortalecer a formação de professores de música em nosso país e o ensino de música nas escolas brasileiras.

\section{FORMAÇÃO DOCENTE NA ARGENTINA}

O sistema educativo nacional argentino compõe-se de serviços educacionais de gestão estatal, privada, cooperativa ou social e está sob a responsabilidade do Estado nacional, das províncias e da Cidade Autônoma de Buenos Aires, que devem garantir seu planejamento, organização, supervisão 
e financiamento. O sistema organiza-se em quatro níveis - educação inicial, educação primária, educação secundária e educação superior - e oito modalidades - educação técnico-profissional, educação artística, educação especial, educação permanente de jovens e adultos, educação rural, educação intercultural bilíngue, educação em contextos de privação de liberdade e educação domiciliar e hospitalar (Ley 26.206/2006, art. 17) (Argentina, 2006).

Historicamente, a formação de professores na Argentina ampliou-se, até o século XX, em dois circuitos paralelos - o universitário, que se destinava às diversas profissões - e o normalista, que atendia o sistema educacional formal (Alliaud, 2013, p. 198). O sistema nacional de formación docente atual prepara profesores - que lecionam disciplinas específicas para o ensino secundário e superior - e maestros - docentes dos níveis de educação inicial e primária. Há dois tipos de instituições superiores: as universidades e os institutos superiores de educación, de caráter não universitário. As principais diferenças entre os dois sistemas estão expostas no Quadro 1.

\begin{tabular}{|c|l|l|}
\hline QUESITOS & \multicolumn{1}{|c|}{$\begin{array}{c}\text { EDUCAÇÃO SUPERIOR } \\
\text { UNIVERSITÁRIA }\end{array}$} & \multicolumn{1}{c|}{$\begin{array}{c}\text { EDUCAÇÃO SUPERIOR NÃO } \\
\text { UNIVERSITÁRIA }\end{array}$} \\
\hline Instituições & $\begin{array}{l}\text { Universidades organizadas em } \\
\text { Departamentos, Faculdades, } \\
\text { Unidades Acadêmicas }\end{array}$ & $\begin{array}{l}\text { Institutos Superiores de Educação } \\
\text { Institutos ou Escolas especializadas } \\
\text { de orientação técnica }\end{array}$ \\
\hline Vinculação & $\begin{array}{l}\text { Ministerio de Cultura y Educación } \\
\text { (Formulam as políticas gerais } \\
\text { juntamente com os Conselhos das } \\
\text { universidades) } \\
\text { Autonomia acadêmica e institucional }\end{array}$ & $\begin{array}{l}\text { Províncias e Municipalidade da } \\
\text { Cidade Autônoma de Buenos Aires }\end{array}$ \\
\hline Cursos & $\begin{array}{l}\text { Graduação } \\
\text { Pós-Graduação }\end{array}$ & Graduação \\
\hline Áreas & $\begin{array}{l}\text { Formação nas diversas áreas } \\
\text { disciplinares }\end{array}$ & $\begin{array}{l}\text { Formação docente para o sistema } \\
\text { educacional } \\
\text { Formação de caráter instrumental } \\
\text { nas áreas humanísticas, artísticas e } \\
\text { técnico-profissionais }\end{array}$ \\
\hline $\begin{array}{c}\text { Conhecimentos } \\
\text { privilegiados }\end{array}$ & Saberes específicos disciplinares & Saberes pedagógicos específicos \\
\hline
\end{tabular}

Quadro 1: Características da educação superior universitária e da não universitária na Argentina. Fonte: elaboração própria.

Os lineamientos curriculares nacionales (Argentina, 2007) regulam os cursos dos institutos superiores e das universidades e orientam a configuração das estruturas curriculares da formação de docentes para os diversos niveis e modalidades do sistema educacional argentino (Figura 1). 


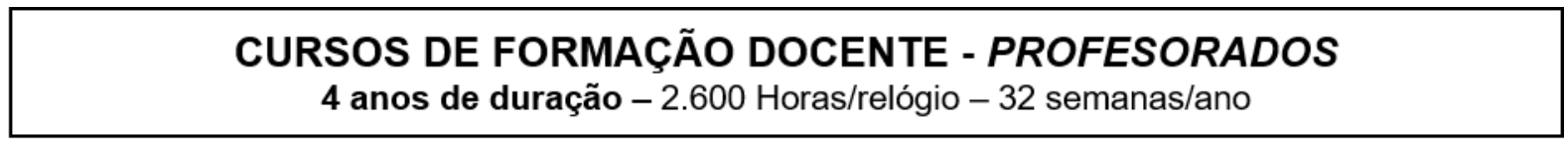

\begin{tabular}{|c|c|c|}
\hline \multicolumn{3}{|c|}{$1^{\circ} \mathrm{CICLO}$ FORMAÇÃO BÁSICA COMUM $-2^{\circ} \mathrm{CICLO:} \mathrm{FORMAÇÃO} \mathrm{ESPECIALIZADA}$} \\
\hline $\begin{array}{l}\text { CAMPOS DE } \\
\text { CONHECIMENTO }\end{array}$ & $\begin{array}{l}\text { ORGANIZAÇÃO DOS } \\
\text { DESENHOS } \\
\text { CURRICULARES }\end{array}$ & MODALIDADES \\
\hline & $\begin{array}{l}\text { Matérias } \\
\text { Seminários } \\
\text { Oficinas }\end{array}$ & $\begin{array}{l}\text { Tipo de conhecimento: } \\
\text { Educação técnico-profissional } \\
\text { Educação Artística }\end{array}$ \\
\hline \multirow{3}{*}{$\begin{array}{l}\text { Formação } \\
\text { Específica } \\
(50 \% \text { a } 60 \%)\end{array}$} & $\begin{array}{l}\text { Trabalhos de Campo } \\
\text { Práticas docentes } \\
\text { Módulos } \\
\text { Unidades curriculares } \\
\text { opcionais }\end{array}$ & $\begin{array}{c}\text { Contextos socioculturais: } \\
\text { Educação rural } \\
\text { Educação em contextos de privação } \\
\text { de liberdade } \\
\text { Educação domiciliar e hospitalar }\end{array}$ \\
\hline & $\begin{array}{l}\text { Sistema de créditos: } \\
\text { Conferências e Colóquios } \\
\text { Seminários de intercâmbio }\end{array}$ & $\begin{array}{l}\text { Grupos específicos de sujeitos: } \\
\text { Educação especial } \\
\text { Educação permanente de jovens e } \\
\text { adultos }\end{array}$ \\
\hline & $\begin{array}{l}\text { Debate de experiências } \\
\text { Ciclos de Arte } \\
\text { Congressos }\end{array}$ & $\begin{array}{l}\text { Tipos de conhecimento, contextos } \\
\text { socioculturais específicos e }\end{array}$ \\
\hline $\begin{array}{c}\text { Formação na } \\
\text { Prática Profissional } \\
\text { (15\% a } 25 \%)\end{array}$ & $\begin{array}{l}\text { Oficinas } \\
\text { Atividades de estudo } \\
\text { independente }\end{array}$ & $\begin{array}{c}\text { específico de sujeitos: } \\
\text { Educação intercultural } \\
\text { Educação intercultural bilíngue }\end{array}$ \\
\hline
\end{tabular}

Figura 1: Ciclos de formação, campos de conhecimento, organização dos desenhos curriculares e modalidades de ensino dos cursos de formação docente na Argentina.

Fonte: elaboração própria (baseado em Argentina, 2007).

As estruturas curriculares ou planes de estudio organizam-se em torno de três campos de conhecimento. O campo de formação geral tem enfoque disciplinar e humanístico, visando a compreensão dos fundamentos da profissão. O de formação específica orienta para o ensino da especialidade para a qual se está formando e para as características do sistema educacional, da especialidade ou da modalidade educativa.

O campo de formação na prática profissional dirige-se à aprendizagem das habilidades para o trabalho docente nas instituições de ensino, sendo um eixo integrador que deve articular-se com os outros dois campos. O estágio (práctica profesional docente) está presente desde o início da formação e vai tornando-se mais complexo até culminar na residência pedagógica integral. 
Esse processo constitui-se em atividades de campo (observação, participação e cooperação em escolas e comunidades com sistematização e análise das informações) e situações didáticas nas instituições formadoras (estudos de caso, análise de experiências) (Argentina, 2007).

\section{INSTITUIÇÕES E OFERTA DE CURSOS PARA FORMAÇÃO DE PROFESSORES DE MÚSICA}

O ensino de música dá-se na educação infantil, primária, secundária e superior (modalidade educação artística), havendo diretrizes específicas para os currículos de cada nível. A formação de professores de música insere-se na educação superior e ocorre nos chamados profesorados en música. $\mathrm{Na}$ Argentina, os cursos de formação de professores são designados profesorados, enquanto os cursos de licenciatura equivalem aos nossos bacharelados (Mateiro, 2010, p. 33).

Na Argentina, há um total de 113 instituições públicas e privadas que oferecem 243 profesorados en música, sendo 14 instituições universitárias e 99 institutos superiores de formação docente - dentre conservatórios, escolas e centros de arte ou de música, como se vê no Quadro 2.

\begin{tabular}{|l|c|c|c|}
\hline \multirow{2}{*}{ INSTITUIÇÕES FORMADORAS } & $\begin{array}{c}\text { TIPO DE } \\
\text { GESTÃO }\end{array}$ & $\begin{array}{c}\text { QUANTIDADE DE } \\
\text { INSTITUIÇÕES }\end{array}$ & $\begin{array}{c}\text { PROFESORADOS } \\
\text { EN MÚSICA }\end{array}$ \\
\hline INSTITUIÇÕES & Pública & 11 & 59 \\
\cline { 2 - 4 } UNIVERSITÁRIAS & Privada & 3 & 2 \\
\hline \multirow{2}{*}{ INSTITUTOS SUPERIORES } & Pública & 86 & 161 \\
\cline { 2 - 4 } & Privada & 13 & 21 \\
\hline \multicolumn{2}{|l}{ TOTAL } & $\mathbf{1 1 3}$ & $\mathbf{2 4 3}$ \\
\hline
\end{tabular}

Quadro 2: Instituições formadoras, tipo de gestão e quantidade, e oferta de profesorados en música. Fonte: elaboração própria.

Mais de 25\% das 113 instituições formadoras são conservatórios de música, que atendem a 21 das 24 províncias do país, além da Cidade Autônoma de Buenos Aires. Em seguida, têm-se outras instituições públicas - escolas ou centros de arte, institutos superiores de formação docente, escolas de música e institutos de arte/educação artística; os institutos superiores privados e, por fim, os departamentos ou faculdades de arte e institutos de música públicos. A predominância na oferta pelo setor público $(86 \%)$ pode ser justificada pela necessidade de o sistema formador suprir as demandas do sistema educacional, visto que a música está nos currículos escolares desde $1884 .^{1}$

\footnotetext{
1 A Ley no 1.420/1884 (Argentina, 1884) estabelece a obrigatoriedade do ensino de música e artes plásticas nas escolas básicas, na Argentina.
} 
Destaca-se a diversidade de tipos de instituições formadoras, que variam entre as que se dedicam mais à formação musical (43\%) - conservatórios, escolas de música, departamentos de música - as que focam na arte em geral (33\%) - como os centros ou institutos de arte/educação artística - e as que oferecem formação docente para diversas áreas (24\%) - como os institutos superiores e as faculdades de humanidades das universidades.

As orientaciones - ênfase dada à formação em cada curso - dos 243 profesorados en música, independentemente da gestão e do tipo de instituição, concentram-se nos profesorados en música con orientación en música ou educación musical (104). Em geral, os egressos desses cursos encaminham-se para escolas do sistema educacional, o que tem demandado uma crescente qualificação de docentes de música. Os profesorados con orientación en instrumento e en canto (90) formam professores para lecionarem, além das escolas básicas, em escolas específicas de música, conservatórios e outros espaços. Registra-se a presença de cursos com foco em dirección coral, composición e dirección orquestal. Tem sido crescente a procura por formação em música popular e a oferta de oito cursos nessa área demostra a abertura de instituições formadoras para outros tipos de música, além da acadêmica.

Os profesorados são designados por distintos nomes, tais como profesorado de música, profesorado en instrumento, profesorado superior de música, profesorado universitario, profesorado de artes, apesar de a titulação do egresso ser profesor de música, de acordo com a legislação vigente. Essa diversidade de nomenclatura ratifica a multiplicidade de denominações dos cursos de formação docente na área de música, em toda a América Latina (Mateiro, 2010).

\section{CONCEPÇÕES DE FORMAÇÃO DE PROFESSORES DE MÚSICA NA ARGENTINA}

As concepções de formação de professores de música na Argentina emergiram dos documentos analisados - leis, resoluções, projetos pedagógicos - e das falas dos gestores e professores entrevistados, bem como dos alunos participantes dos grupos focais.

O direito à educação e ao conhecimento como um bem público garantido pelo Estado é um dos pilares que sustenta a Ley de Educación Nacional (Argentina, 2006). A formação docente é vista como uma oportunidade de desenvolvimento da formação integral das pessoas e a docência é concebida em três eixos: docência como prática de mediação cultural, docência como trabalho profissional institucionalizado e docência como prática pedagógica.

A concepção de professor como sujeito social emerge desses três eixos e transparece na obrigatoriedade de interação entre algumas unidades curriculares do campo de la formación específica e do campo de la formación en la práctica que contemplam os diversos sujeitos de ensino, visando a preparação do docente para trabalhar em diferentes contextos (Argentina, 2007). Professores e alunos dos profesorados en música também declararam comungar dessa concepção, cientes de sua responsabilidade social para promover uma aprendizagem mais significativa para os estudantes. 
A concepção que carrega a dicotomia entre formação prática e teórica foi identificada, principalmente, quando se tratou de diferenças entre as instituições formadoras. Alguns docentes declararam que há uma propensão de a formação nos conservatórios ser mais prática, mais focada no futuro campo laboral, enquanto a formação universitária tende mais à teoria, enfatizando a pesquisa acadêmica, diminuindo o tempo de contato do estudante com as escolas básicas.

O fato de a instituição ser ou não universitária tem efeitos sobre as relações entre o sistema formador e o sistema educacional. Segundo Vaillant (2013), as escolas normais, que formavam maestros, deram origem à maioria das instituições não universitárias, ambas vinculadas às Secretarias ou Ministérios de Educação, o que permite maior articulação entre os cursos de formação do professor e a escola básica. Quando as universidades passaram a oferecer a formação docente, esse vínculo tradicional com as escolas rompeu-se.

Como, na Argentina, apenas $12 \%$ das instituições formadoras na área de música são universitárias, é possível que o impacto da entrada das universidades na formação docente tenha sido menor. Em contrapartida, os conservatórios, que equivalem a mais de $25 \%$ dessas instituições, embora estejam mais próximos da comunidade, por ofertarem cursos em nivel básico e técnico para milhares de alunos, afastam-se dos contextos reais de seus discentes por terem, de modo geral, um ensino focado na transmissão da cultura musical consagrada como legítima (Carabetta, 2014, p. 40). Portanto, os conhecimentos privilegiados tanto nos conservatórios quanto nas universidades distanciam-se, muitas vezes, da escola básica.

A relação entre as instituições formadoras e as escolas efetiva-se, especialmente, nos momentos de estágio que ocorrem desde o início da formação de professores, partindo da observação até à intervenção pedagógica. Além das escolas públicas, os alunos estagiam em escolas privadas, em escolas especializadas de música e na própria instituição formadora.

A dicotomia - formação do músico versus formação do professor de música - perpassa pela história da formação docente, pelos projetos pedagógicos dos cursos e pelas falas e ações de professores e até mesmo de alunos. A formação do professor especializado nas diversas áreas somente se consolidou, na Argentina, no século XX. Por isso, foram os egressos dos conservatórios que, inicialmente, deram aulas de música nas escolas, apesar de não terem tido preparação pedagógica para tal (Carabetta, 2014, p. 18).

Nos anos de 1970, criaram-se cursos de educação musical, visando a formação do profesor de educación musical para o ensino de música nas escolas básicas, diferindo daqueles que preparavam o professor de instrumento ou canto. Na década de 1990, detectou-se um desequilíbrio na formação de professores de música, pois apesar de a preparação pedagógica ser intensa, a musical era frágil e comprometia o ensino de música nas escolas. Em decorrência disso, passou-se a conceber uma formação docente que preparasse o músico-docente, unindo os dois aspectos. Uma das ações implementadas foi possibilitar que o aluno escolhesse seu instrumento, em vez de obrigá-lo a estudar piano, violão e flauta doce, como se fazia nos cursos de educação musical. 
Assim, a concepção que sustentou a reforma curricular dos profesorados en música, a partir dos anos 2000, foi a de que era necessário ser músico e docente, rompendo-se com a cisão transcorrida nos anos de 1970. Pretendeu-se também extinguir o pensamento de que o professor de educação musical, diga-se, aquele que dá aulas nas escolas, "vale menos" que os professores de instrumento ou canto.

Apesar disso, ainda há diferenças entre os profesorados en música com foco em educação musical e aqueles com orientación em alguma especialidade - instrumento, canto, regência, composição, etc. Carabetta (2008) diz que a formação do professor nessas orientaciones continua muito focada na performance musical e pouco na docência. Ela declara que a dicotomia entre o músico e o docente, bem como a supervalorização do músico profissional, aumentam a ambiguidade na identidade profissional do egresso, de modo que o professor de música quase nunca se vê como músico e o músico profissional não quer ser confundido com um docente, mesmo que ele dê aulas de instrumento (Carabetta, 2008, p. 139). Percebe-se que as próprias instituições formadoras contribuem para forjar as duas identidades, apesar de ofertarem cursos que visam à formação do professor de música, seja para lecionar aulas de educação musical nas escolas ou de instrumento, em espaços diversos.

É premente esclarecer que a concepção de formação do professor de educação musical como um músico e professor difere-se da concepção de músico-professor como um artista civilizador que visa à virtuosidade técnica e dá preponderância à performance (Pereira, 2013, p. 149). Apesar dos problemas ainda existentes, o que se propõe, na Argentina, é uma integração entre formação musical e pedagógica, de tal maneira que o egresso seja e se sinta um músico-professor e um professor-músico. Ter um profissional que seja professor e músico valoriza o ensino de música nas escolas básicas e rompe com a "(falsa) crença de que não há necessidade de uma preparação específica para a atuação docente, como expressa o ditado popular 'quem não sabe ensina'" (Penna, 2007, p. 51).

As recentes reformulações nos planes de estudio, em todas as jurisdições argentinas, têm buscado melhorias na formação dos professores de música, verificando-se a ocorrência gradual de mudanças, segundo relatos de entrevistados na pesquisa. Entretanto, Pereira (2013, p. 146) traz à tona a questão de que concepções e ações sustentadas pelo habitus conservatorial podem ser mantidas, a despeito das reformas curriculares, que podem se tornar "cosméticas e periféricas".

Pereira (2013) acredita que professores e estudantes de música apresentam um habitus conservatorial, "um conjunto de disposições de habitus ${ }^{2}$ elitista e hierarquizante, uma perfeita segunda natureza, que impede

\footnotetext{
2 Habitus, conceito de Bourdieu, é o que "permite sustentar a existência de uma estrutura social objetiva, baseada em múltiplas relações de luta e dominação entre grupos e classes sociais - das quais os sujeitos participam e para cuja perpetuação colaboram através de suas ações cotidianas, sem que tenham plena consciência disso [...]" (Nogueira; Nogueira, 2009, p. 26).
} 
o desenvolvimento de propostas de democratização da prática musical" (Setton, 2013, p. 16). A cultura musical dominante é mantida pelo conservatório, determinando-se o tipo de música e de práticas musicais que serão legitimadas, o que estabelece um sistema de hierarquização. A visão de música, de músico e de ensino musical advinda é hegemônica, pois foi naturalizada e é considerada como realidade e verdade. Dessa maneira, "outras formas de se pensar e fazer música são negadas, excluídas e destituídas de valor" (Pereira, 2013, p. 135).

Assim também, o modelo conservatório (Shifres; Gonnet, 2015) valoriza os desempenhos individuais, o virtuosismo e a relação diática - relação discípulo-mestre - e explicita que a notação musical determina o que é musical e o que é extramusical. Além disso, as categorias - música acadêmica, popular, étnica - são forjadas nos próprios âmbitos acadêmicos ocidentais, mantendo-se uma hierarquia.

Carabetta (2014, p. 51) elucida que, como os profesorados en educación musical na Argentina foram criados nos conservatórios, nos anos de 1980, em que as politicas neoliberais desenvolvidas nos países centrais exerciam forte influência nos países periféricos, o modelo de Educação Musical Estética ${ }^{3}$ encontrou muitos adeptos no país vizinho. Assim sendo, o modelo de formação de professores de música na Argentina tendeu a reproduzir a consagração da música erudita europeia, de acordo com o pensamento da estética pura.

Junto ao privilégio dado à formação do músico, vem a preferência pelas aulas individuais, evidenciando-se a relação mestre-aprendiz. Tal relação professor-aluno, modificada pelo habitus conservatorial, coloca o docente, em geral, como o detentor do saber, que os alunos devem ter como exemplo inquestionável e única referência. Dois estudantes que participaram da pesquisa falaram sobre a presença de um rigor técnico associado ao estudo individual e destacaram a importância de haver momentos coletivos durante a formação para auxiliá-los na futura prática docente.

Os efeitos do habitus conservatorial podem gerar descompassos entre a formação dada aos professores de música e a realidade das escolas, pois ocorre de os alunos repetirem as experiências marcadas pelo habitus conservatorial em suas atividades nas escolas, durante os estágios, conforme declara Carabetta (2014). A autora explica que a presença quase exclusiva da música erudita nos conservatórios significa não apenas a seleção do respectivo gênero para ser estudado, mas também a adoção de uma série de características como seriedade, originalidade e universalidade, atribuídas a ela, que são utilizadas por professores e alunos para analisar, classificar e julgar outras diferentes expressões musicais (Carabetta, 2014, p. 43).

\footnotetext{
3 A Educação Musical Estética, concebida em 1958, nos Estados Unidos, originou-se de debates sobre o valor da educação musical na educação geral e propõe "[...] pensar en la música como obra de arte, promover la familiaridad de los estudiantes con las obras de los 'grandes clásicos' de la música europea occidental, [y] adherir a una visión jerárquica de la música y sus supuestos valores intrínsecos” (Carabetta, 2014, p. 51).
} 
Os principais aspectos do habitus conservatorial, apontados por Pereira (2013), que foram evidenciados no contexto argentino, demonstram a existência de hierarquização: entre música acadêmica e outras músicas; entre estratégias de ensino individuais e grupais; entre professor e aluno; entre intérprete e ouvinte, e entre teoria e prática, além do foco na aprendizagem instrumental/performance estar presente em muitos profesorados. Apesar do avanço verificado pela adoção de novos conhecimentos nos currículos e a abertura para outras músicas, como é o caso do aumento da oferta de profesorados con orientación en música popular, ainda há que se aprofundar nas reflexões sobre os efeitos do habitus conservatorial na formação de professores de música no país vizinho.

A análise das concepções de formação de professores de música, tomando como referência os paradigmas de formação docente propostos por Zeichner (1983), apontou para a ocorrência do paradigma "tradicional-artesanal", principalmente em aulas de instrumento. Essa perspectiva assenta-se no conceito de ensino como uma arte e dos professores como artífices, sendo o conhecimento sobre o ensino construído por tentativa e erro. Os futuros professores são tidos como receptores passivos e a relação mestre-aprendiz é considerada como a melhor maneira de se transmitir ao estudante o "conhecimento-cultural" que os bons professores detêm (Zeichner, 1983, p. 5). O aluno, em geral, não tem espaço para expor suas opiniões nem fazer escolhas, e a aquisição de competências não garante o sucesso do futuro professor nas novas situações, dificultando a transposição didática, pois os conteúdos aprendidos na formação estão muito dissociados das realidades das escolas.

Outro paradigma encontrado foi o "comportamentalista", que concebe a educação como uma "ciência aplicada", na qual outras pessoas formulam as tarefas que o professor deverá executar, sendo o futuro docente um receptor passivo (Zeichner, 1983, p. 4). Foram verificadas características desse paradigma em disciplinas de prática instrumental/vocal que permanecem focadas no desenvolvimento da técnica virtuosística e no resultado individual do aluno e estão mais relacionadas aos profesorados con orientación en instrumento, que acabam por privilegiar a performance musical.

Segundo Zeichner (1983), o paradigma "personalista" tem o foco na formação humanística e personalizada e os estudantes são agentes ativos. O programa de formação tem conteúdos baseados em suas necessidades e preocupações, sendo os resultados medidos em termos de efeitos sobre os indivíduos e não sobre sistemas sociais (Zeichner, 1983, p. 4). Tais atributos foram encontrados no denominado espacio de definición institucional dentro das estruturas curriculares dos profesorados en música em que há unidades curriculares que visam atender as demandas individuais dos alunos. Como exemplos tem-se a possibilidade de escolha de um instrumento principal, que veio auxiliar na formação musical do professor, respeitando sua afinidade por um determinado instrumento. Também se enquadram, nesse paradigma, momentos de estágio supervisionado em que professores dão atenção individualizada aos alunos, atentando-se para suas necessidades pessoais dentro do processo de formação docente. 
Distinguiu-se o paradigma "baseado na pesquisa" nos programas de diversas unidades curriculares, em espaços de reflexão e ao se estimular o desenvolvimento da criticidade dos alunos. Além disso, o perfil do egresso é pensado como um professor que tem autonomia, que é flexivel e acolhe a diversidade. Sob o prisma desse paradigma, o futuro professor é considerado um sujeito ativo e conduzido à problematização daquilo que em geral é tomado como certo, desenvolvendo a capacidade da "ação reflexiva" (Dewey, 1933 apud Zeichner, 1983) e tendo um papel maior na orientação dos contextos educativos (Zeichner, 1983, p. 6). Nos profesorados en música, tal paradigma foi identificado ainda nas muitas propostas de trabalho coletivo; na ampliação e diversificação dos formatos das unidades curriculares e na flexibilização da avaliação; na criação de espaços curriculares para o estudo dos contextos e dos sujeitos; nas propostas de se trabalharem os diversos gêneros e estilos musicais, e na abertura de espaços de avaliação institucional, de maneira coletiva, envolvendo professores e alunos.

Portanto, assim como afirma Zeichner (1983, p. 15), pode-se verificar, em um mesmo contexto, características dos vários paradigmas de formação docente, pois, apesar de haver tendências dominantes, no momento de sua execução, ocorre uma mistura de orientações vindas de perspectivas individuais dos sujeitos envolvidos na formação.

\section{Modelos DE FORMAÇÃO DE PROFESSORES DE MÚSICA}

Os modelos de formação de professores de música apontados por Mateiro (2010) constituíram-se em outra referência na investigação realizada na Argentina. A partir do estudo de 45 estruturas curriculares de oito países sul-americanos, ${ }^{4}$ a autora identificou três modelos de formação docente e detectou a diversidade de instituições formadoras (faculdades de educação ou de belas artes, conservatórios de música, dentre outras) e de terminologias para os cursos (profesorado en educación musical, profesorado de artes en música, profesorado de educación superior en música, etc.).

O primeiro modelo de formação docente centra-se no conhecimento da música enquanto fenômeno, atividade e objeto de estudo. Os cursos têm a música como área principal e uma especialidade (habilitação ou orientación) em composição, direção coral, canto, execução instrumental, educação musical, entre outras. A ênfase está nas disciplinas de conteúdo musical (cerca de $50 \%$ do total de horas), demonstrando a concepção de que o professor deve ser, antes de tudo, músico (Mateiro, 2010).

O segundo modelo tem como principal área a pedagogia e prioriza as disciplinas que se referem aos aspectos da educação, formação, ensino, aprendizagem, instrução e didática. Os cursos, oferecidos por Faculdades de Educação ou de Humanidades, denominam-se Educação com especialidade

\footnotetext{
4 Argentina (9); Bolívia (2); Brasil (15); Chile (8); Colômbia (1); Equador (2); Paraguai (1) e Venezuela (7) (Mateiro, 2010).
} 
em educação musical ou pedagogia musical e formam professores para lecionar na educação primária e secundária (Mateiro, 2010).

No terceiro modelo, foca-se a área de artes com especialidade em música, artes visuais, artes cênicas, artes cinematográficas ou produção cultural. Os cursos iniciam-se com a ampliação dos conhecimentos gerais dos diferentes campos artísticos e, em seguida, o aluno opta por uma especialidade para dar continuidade à sua formação (Mateiro, 2010). A arte é vista de maneira integrada na educação de crianças e jovens, constando como uma única disciplina no currículo escolar. Tem-se como exemplo o Brasil, que adotou essa proposta de formação nos anos de 1970, com a criação dos cursos de educação artística que integravam as diversas subáreas de arte, culminando na chamada polivalência. A Figura 2 expõe os três modelos de formação de professores de música (Mateiro, 2010).

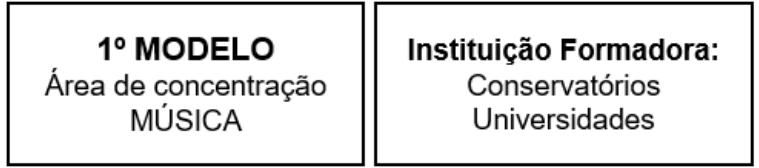

\section{$2^{\circ}$ MODELO}

Área de concentração PEDAGOGIA

Instituição Formadora:
Faculdades de Educação
ou Humanidades

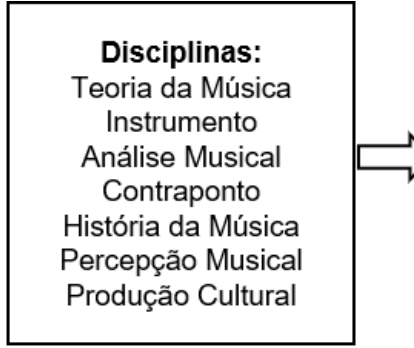

MÚSICO COM ESPECIALIDADE EM EDUCAÇÃO MUSICAL

Percepção Musical

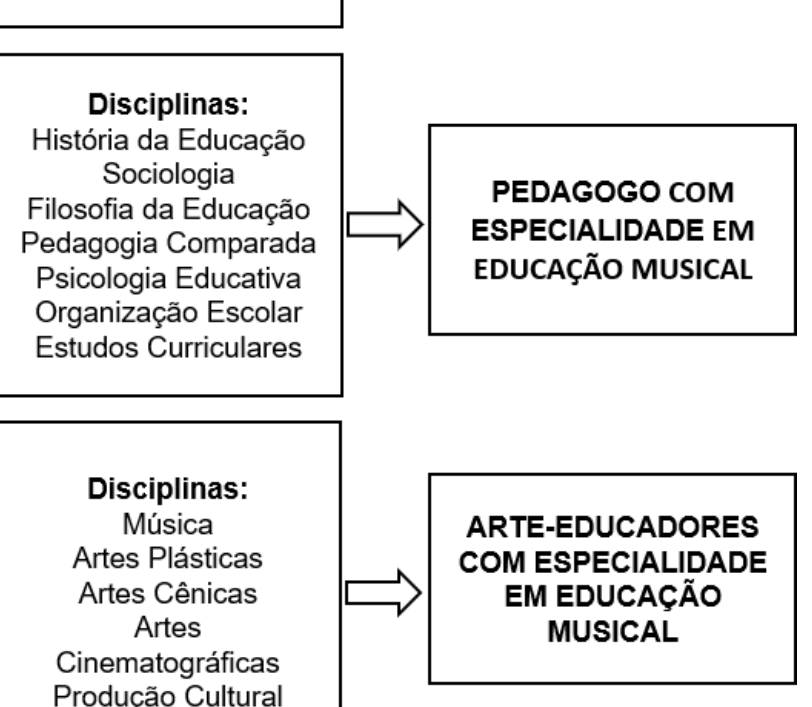

\section{Instituição Formadora: \\ Faculdades de Artes Universidades}

Figura 2: Modelos de formação de professores na América Latina. Fonte: elaboração própria (baseado em Mateiro, 2010).

A partir da análise das instituições formadoras e dos profesorados en música e de relatos dos sujeitos entrevistados na pesquisa de que trata este artigo, pode-se compreender que o primeiro modelo - que visa à formação 
do músico - ainda se encontra vigente nos profesorados en música argentinos, em especial naqueles com orientación en instrumento/canto e outras especialidades. Um quarto modelo ${ }^{5}$ foi identificado nos profesorados en música sem orientación ou con orientación en educación musical. Do mesmo modo, Mateiro (2018, p. 107) já aponta, no contexto brasileiro, um "modelo de formação que propõe de modo integrado o estudo entre música e pedagogia, [...] que procur[a] equilibrar e relacionar os conhecimentos técnicos musicais com os conhecimentos didáticos e pedagógicos", visando habilitar o professor para trabalhar no ensino de música nas escolas.

Tal modelo pretende abolir as hierarquias entre os conhecimentos pedagógicos e os específicos ao se entender que ambos são fundamentais na formação do professor de música. À primeira vista, esse modelo identificado nos profesorados en música pode parecer semelhante àquele que tem como foco a formação do músico, colocando a formação pedagógica como um acréscimo. Entretanto, há pelo menos dois aspectos que os diferenciam: a formação pedagógica acontecer desde o primeiro ano de formação e a mudança na concepção do que significa "ser músico".

Ampliando-se o que se considera "ser músico", é possivel vislumbrar a formação de professores de música a abarcar não apenas os músicos virtuosos, os artistas com elevado nivel técnico na performance musical. Um músico, dentro dessa perspectiva, é aquele que conhece os elementos da linguagem musical, mas não necessariamente todas as regras de composição, contraponto e harmonia tradicionais. É um músico que toca um instrumento ou canta, mas não exatamente as obras mais destacadas do repertório erudito europeu. É um músico que utiliza não apenas o raciocínio e o modelo de um mestre para desenvolver suas performances, mas também sua sensibilidade, sua criatividade, seu corpo e tudo aquilo que aprendeu tanto nos livros e na escola quanto em ambientes não formais (em casa, na rua, com seus colegas, etc.).

Carabetta (2014) aponta o pensamento praxial na educação musical como fundamento para uma nova perspectiva de formação docente. Nesse sentido, a música é vista como linguagem simbólica e portadora de significados, sendo produto de uma cultura em determinado tempo; além disso, há uma valorização dos contextos e de experiências anteriores dos alunos, seus interesses e habilidades (Carabetta, 2014, p. 185).

Assim sendo, é viável que instituições formadoras consigam oferecer currículos mais flexiveis que considerem igualmente a importância da preparação musical e pedagógica dos estudantes, criando um amálgama, como já conceituava Tardif (2012, p. 36), "mais ou menos coerente, de saberes oriundos da formação profissional e de saberes disciplinares, curriculares e experienciais".

5 Denominamos "quarto modelo" aquele que está em fase de consolidação - o modelo de formação do professor de música - considerando que ele vem após os três modelos estudados e delineados por Mateiro (2010). 
$\mathrm{Na}$ Argentina, para se designar essa concepção de formação docente e o perfil daquele que vai ensinar música, tem-se utilizado a expressão "músico-professor". Entretanto, propomos que, para o citado "quarto modelo", utilizemos a denominação "professor de música", assim justificado:

a) Pelo fato de a designação músico-professor ser empregada, com frequência, para indicar o profissional resultante do primeiro modelo de formação de professores de música, caracterizado anteriormente.

b) Pela necessidade de se diferenciar o modelo de formação do professor de música da concepção de músico-professor, impregnada pelo habitus conservatorial (Pereira, 2013), que pensa em formar, primeiro, um performer virtuoso, e em segundo plano, oferecer a formação pedagógica em poucas disciplinas. Essa concepção é consoante com os paradigmas "tradicional-artesanal" e "comportamentalista" (Zeichner, 1983) e também nos remete à fórmula $3+1$, dentro da visão aplicacionista da formação de professores (Diniz-Pereira, 2008, p. 257), em que os conhecimentos específicos são tratados no início do curso e os pedagógicos, ao final.

c) Pela importância de se reforçar o uso da palavra "professor" - em vez de educador musical - visando fortalecer a identidade profissional $^{6}$ do professor que trabalha no âmbito do ensino de música, especialmente, nas escolas de educação básica. Ressaltamos que o educador musical é uma categoria mais ampla, que abarca tanto aqueles egressos de cursos superiores de formação docente (os professores de música) quanto "profissionais não-habilitados para o exercício do magistério” (Diniz-Pereira, 2008, p. 256), que se dedicam à educação musical, nos mais diversos contextos, tais como artistas que fazem espetáculos de caráter educativo e pessoas que trabalham em projetos sociais ou culturais como oficineiros, mesmo sem ter formação docente.

Portanto, o modelo de formação do professor de música propõe uma integração entre a formação musical e pedagógica, que leva a duas questões centrais: a conscientização de que a profissão para a qual se está preparando o egresso é a de professor e que esse professor, cuja função é exercer a atividade de ensino, terá um perfil profissional - professor de música. Há que se trabalhar para a consolidação desse perfil, visando à construção da profissionalidade docente do professor de música (Pires, 2015), em relação aos espaços de atuação profissional e à sua identidade como professor.

6 Ver Pires (2015) e Mateiro $(2010,2018)$. 


\section{CONTRIBUIÇÕES DA PESQUISA PARA A FORMAÇÃO DE PROFESSORES DE MÚSICA}

$\mathrm{Na}$ última parte deste artigo, apontamos algumas contribuições da pesquisa sobre a formação de professores de música na Argentina para o Brasil, destacando alguns aspectos:

1. A educação musical escolar e a formação de professores de música:

$\mathrm{O}$ fato de haver um ensino de música estruturado no sistema educacional argentino, desde 1884, afeta de modo sensivel a formação de professores de música e pode nos servir de exemplo. Decorre disso que os estudantes, normalmente, encontram professores de música para os acolherem durante as atividades de estágio. A oferta de cursos de música, dentro da modalidade educação artística na educação secundária, também possibilita a entrada de alunos nos profesorados en música, em busca de qualificação. Em contrapartida, aqui no Brasil, há ainda expressiva ausência do ensino de música nas escolas, o que restringe as experiências de nossos licenciandos durante o estágio.

\section{A concepção do professor como sujeito social:}

Outro aporte trazido da Argentina é a concepção do professor como sujeito social que está presente tanto nos documentos oficiais quanto nas falas dos entrevistados. Isso pode nos ajudar a consolidar a identidade dos egressos dos cursos de licenciatura em música como um docente, cuja função está diretamente ligada a um compromisso com a sociedade na qual vai trabalhar. As questões acerca da ética profissional também se inserem nesse tema e foram destacadas por Pires (2015), ao apontar o conhecimento ético como um pilar na formação do professor de música. A autora esclarece que "são conhecimentos que tocam na relação ética com as pessoas e configuram-se como componente formativo necessário aos professores em formação para o entendimento das complexas situações de ensino" (Pires, 2015, p. 295-296).

3. A estruturação dos currículos e o estágio supervisionado:

No que concerne à estruturação dos currículos, dois aspectos adotados na Argentina - os diferentes formatos das unidades curriculares (disciplinas, seminários, oficinas, projetos, laboratórios) e os três regimes de promoção que são escolhidos pelos alunos (directo, indirecto ou libre) mostram-nos, respectivamente, possibilidades de haver maior flexibilidade na organização dos conteúdos e a promoção da autonomia dos estudantes. Queiroz (2017, p. 151) detectou, em currículos de cursos superiores de música no Brasil, a adoção "de um modelo hegemônico de organização curricular, que trabalha os conhecimentos e saberes musicais agrupados em 'disciplinas' específicas". Em decorrência disso, quanto mais disciplinas se ofertam, menores são as cargas horárias e "mais fragmentado é o fenômeno musical" (Queiroz, 2017, p. 151). O autor citou os estágios e as atividades acadêmico-científico-culturais como dois espaços curriculares que permitem a realização de práticas em música mais abrangentes e integradas, mas observou que eles "representam 
uma parte incipiente do todo, quantitativamente irrelevante se comparada à totalidade dos cursos / habilitações analisados" (Queiroz, 2017, p. 153). Dessa maneira, considerar os diversos formatos de organização dos conteúdos curriculares utilizados na Argentina pode contribuir para que se transcenda o enfoque disciplinar vigente nas licenciaturas em música no Brasil.

Do mesmo modo, pensar no estágio desde o início do curso, como se faz na Argentina, poderá auxiliar no fortalecimento de nossas licenciaturas e relações entre instituições formadoras e escolas de educação básica. Como o estágio supervisionado, no Brasil, inicia-se a partir da segunda metade dos cursos, posterga-se o contato direto dos licenciandos com as escolas. As experiências brasileiras em que mais se tem promovido essa aproximação são as que ocorrem no Programa Institucional de Bolsas para Iniciação à Docência (Pibid). Não obstante, tal programa, por não se configurar como estágio curricular obrigatório, não atende a todos os estudantes.

4. A valorização da produção musical do país e da América Latina:

Outra característica da formação de professores de música na Argentina é a valorização da produção musical do país e da América Latina. Apesar das dificuldades apontadas por Carabetta (2008) para se incorporar a música popular nos conservatórios de música, devido ao predominio ainda hoje da música erudita europeia, constatou-se, nos planes de estudio, diversas unidades curriculares dedicadas à música argentina e à latino-americana.

Em contrapartida, Queiroz (2017, p. 149), estudando sobre a colonialidade na educação superior em música no Brasil, declara que "[...] cerca de $85 \%$ dos conhecimentos e saberes ofertados pelos cursos/habilitações, denominados de cursos de música, tanto nos bacharelados quanto nas licenciaturas, são relacionados mais diretamente ao universo da música erudita". O autor questiona a exclusão de músicas brasileiras, latino-americanas e de outras partes do mundo em tais currículos.

5. A concepção de formação do professor de música:

A ideia de se buscar um equilíbrio entre os conhecimentos pedagógicos e os musicais na formação docente foi evidenciada em alguns profesorados en música na Argentina. A opção de se conceder aos alunos o direito de estudar um instrumento principal, à sua escolha, tem motivado seus estudantes, tornando-se um aspecto significativo nesse processo. Pode-se trazer para os contextos brasileiros, considerar-se a concepção de se formar professores que sejam músicos, aumentando os espaços das práticas musicais, sobretudo nos cursos com habilitação em educação musical, que não têm foco na performance instrumental/vocal. Tal concepção está diretamente vinculada ao quarto modelo de formação de professores, cujo egresso será o "professor de música".

6. Futuros estudos sobre formação de professores de música:

Esta pesquisa indicou possibilidades de futuros estudos, como estabelecer comparações entre cursos de licenciatura em música do Brasil 
e profesorados argentinos, dando visibilidade ao estágio e às relações entre instituições formadoras e escolas; ou, ainda, analisar propostas curriculares de um número grande de profesorados en música con orientación en educación musical argentinos e de licenciaturas brasileiras em música, a fim de verificar a presença e/ou a consolidação do chamado "quarto modelo" de formação de professores de música.

Por fim, sugerimos que pesquisas sobre formação de professores de música devem se expandir, inclusive abarcando outras realidades latino-americanas. Reiteramos a importância do papel do professor de música como um sujeito social, comprometido com a democratização das músicas das diversas culturas e épocas. Do mesmo modo, acreditamos ser possível haver uma sólida formação musical e pedagógica, que rompa com as hierarquias entre os dois campos e estabeleça diálogos, concebendo, assim, profissionais que sejam e sintam-se professores de música.

\section{REFERENCIAS}

ALLIAUD, Andrea. La formación docente en Argentina. Aproximación a un análisis político de la situación. Itinerarios Educativos, [s. l.], v. 6, p. 197214, 2012-2013.

ARGENTINA. Ley 1420 [de 1884]. Ley reglamentando la Educación Común. Buenos Aires: Congreso de la Nación, 1884. Disponivel em: https://www. cultura.gob.ar/media/uploads/ley_1420.pdf. Acesso em: 20 out. 2020.

. Ministerio de Educación. Ley $n^{\circ}$ 26.206, de 14 de diciembre de 2006. Ley de Educación Nacional. Buenos Aires: Ministerio de Educación, 2006.

Consejo Federal de Educación. Instituto Nacional de Formación Docente. Resolución $n^{\circ}$ 24/2007. Lineamientos Curriculares Nacionales para la Formación Docente Inicial. Buenos Aires: Consejo Federal de Educación, 2007.

BARDIN, Laurence. Análise do conteúdo. Lisboa: Edições 70, 2009.

CARABETTA, Silvia. Sonidos y silencios en la formación de los docentes de música. Buenos Aires: Maipué, 2008.

Ruidos en la educación musical. Buenos Aires: Maipué, 2014.

DINIZ-PEREIRA, Júlio Emílio. A formação acadêmico-profissional: compartilhando responsabilidades entre universidades e escolas. In: TRAVERSINI, Clarice; EGGERT, Edla; PERES, Eliane; BONIN, Iara (org.). Trajetórias e processos de ensinar e aprender: didática e formação de professores. Porto Alegre: EDIPUCRS, 2008. v. 1, p. 253-267. 
MATEIRO, Teresa. Músicos, pedagogos y arte-educadores con especialidad en educación musical: un análisis sobre la formación docente en países suramericanos. Profesorado: revista de currículum y formación del profesorado, Granada, v. 14, n. 2, p. 29-40, 2010.

Sobre os modos de aprender e ensinar: alternativas para a formação docente em música. In: MIGLIORINI, Jeanine Mafra (org.). Reflexões sobre a arte e o seu ensino: v. 1. Ponta Grossa: Atena Editora, 2018. p. 103-116.

NOGUEIRA, Maria Alice; NOGUEIRA, Cláudio M. Bourdieu e a educação. 3. ed. Belo Horizonte: Autêntica, 2009. (Pensadores \& Educação, v. 4).

PENNA, Maura. Não basta tocar? Discutindo a formação do educador musical. Revista da Abem, Porto Alegre, v. 16, p. 49-56, 2007.

PEREIRA, Marcos Vinícius M. O ensino superior e as licenciaturas em música: um retrato do habitus conservatorial nos documentos curriculares. Campo Grande: Ed. UFMS, 2013.

PIRES, Nair. A profissionalidade emergente dos licenciandos em música: conhecimentos profissionais em construção no PIBID música. 2015. Tese (Doutorado em Educação) - Faculdade de Educação, Universidade Federal de Minas Gerais, Belo Horizonte, 2015.

QUEIROZ, Luís Ricardo Silva. Traços de colonialidade na educação superior em música do Brasil: análises a partir de uma trajetória de epistemicídios musicais e exclusões. Revista da Abem, Londrina, v. 25, n. 39, p. 132-159, 2017.

SETTON, Maria da Graça Jacintho. Prefácio. In: PEREIRA, Marcos Vinícius M. O ensino superior e as licenciaturas em música: um retrato do habitus conservatorial nos documentos curriculares. Campo Grande: Ed. UFMS, 2013. p. 15-17.

SHIFRES, Favio; GONNET, Daniel. Problematizando la herencia colonial en la educación musical. Epistemus: revista de estudios en música, cognición y cultura, [s. l.], v. 3, n. 2, p. 51-67, 2015.

TARDIF, Maurice. Saberes docentes e formação profissional. 14. ed. Petrópolis: Vozes, 2012.

VAILLANT, Denise. Formación inicial del profesorado en América Latina: dilemas centrales y perspectivas. Revista Española de Educación Comparada, [s. l.], n. 22, p. 185-206, 2013.

ZEICHNER, Kenneth M. Alternative paradigms of teachers education. Journal of Teacher Education, [s. l.], v. 34, n. 3, p. 3-9, 1983. 
Gislene Marino é professora na Escola de Música da Universidade do Estado de Minas Gerais (EsMu/UEMG) e chefe do Departamento de Formação Pedagógica. Doutora em Educação (Doutorado Latino-Americano - FaE/UFMG) e mestre em Educação (FaE/UFMG); Especialista em Educação Musical, licenciada em Música e bacharel em Música/Piano (Escola de Música/ UFMG). Exerceu funções de gestão na EsMu/UEMG: coordenação do Curso de Bacharelado em Música (2000-2003); chefia do Departamento de Teoria Musical (2004-2008) e diretoria da EsMu/UEMG (2008/2012). Coordenou o Subprojeto Música do Pibid/UEMG (2015-2017). Coautora dos livros didáticos Piano 1: arranjos e atividades (2001, 1.ed.; 2015, 2.ed.) e Piano 2: arranjos e atividades (2009). https://orcid.org/0000-0002-7989-9519

Júlio Emílio Diniz-Pereira é professor do Programa de Pós-Graduação em Educação da Universidade Federal de Minas Gerais e coordenador do Doutorado Latino-Americano em Educação (PPGE/FaE/UFMG). Doutor em Educação (University of Wisconsin-Madison, EUA). Professor visitante em universidades nos Estados Unidos - North Carolina State University e University of Wisconsin-Madison e na Universidad de Playa Ancha, no Chile. Coordena a Coleção Docência da Editora Autêntica, de Belo Horizonte. Autor dos livros Formação de professores: pesquisas, representações e poder (2000) e How the dreamers are born: struggles for social justice and the identity construction of activist educators in Brazil (2013). https://orcid.org/0000-0002-5401-4788 